\title{
Adaptation of Fire Blight Forecasting to Optimize the Use of Biological Controls
}

\author{
K. B. Johnson, V. O. Stockwell, and T. L. Sawyer, Department of Botany and Plant Pathology, Oregon State Uni- \\ versity, Corvallis 97331
}

\begin{abstract}
Johnson, K. B., Stockwell, V. O., and Sawyer, T. L. 2004. Adaptation of fire blight forecasting to optimize the use of biological controls. Plant Dis. 88:41-48.

We investigated adaptation of fire blight forecasting concepts to incorporate and optimize the use of biological agents for disease suppression. The effect of temperature on growth of the bacterial antagonists, Pseudomonas fluorescens A506 and Pantoea agglomerans C9-1S, and of the pathogen Erwinia amylovora 153N, on pear and apple blossoms was evaluated in growth chamber and screenhouse experiments. New blossoms were inoculated with the strains and subsequent growth was measured over $96 \mathrm{~h}$. Bacterial growth rates on blossoms were described as functions of temperature. A degree hour-based "bacterial growth index" (96-h moving total of degree hours $>10^{\circ} \mathrm{C}$ ) was created to assess conduciveness of orchard environments for antagonist colonization. A comparison of this index to a disease risk index indicated that biocontrol treatments could be timed such that the antagonists could be expected to grow to an effective population size before the disease index shifted from "low" to "moderate" risk. For six pear- and apple-production areas of Oregon and Washington, regression of actual values of the bacterial growth and disease risk indices on index values derived from 4-day temperature forecasts resulted in coefficients of determination that averaged 0.75 . The "bacterial growth index" and its estimation via temperature forecasts were incorporated into a decision matrix designed to guide optimal treatment timing.
\end{abstract}

Fire blight, caused by the bacterium $E r$ winia amylovora, is an important disease of pear and apple grown in the United States and in other regions of the world. Management of fire blight focuses on prevention of infection combined with pruning of diseased branches to maintain tree health and to eliminate sources of inoculum $(4,18,29)$. Suppression of blossom infection is key in fire blight management because the running cankers that originate from diseased blossoms can cause significant damage to a tree, and these cankers provide the inoculum for secondary phases of the disease. Blossom infection requires the development of an epiphytic population of the pathogen on floral surfaces (27). In the United States, streptomycin sulfate is applied commonly during bloom to suppress epiphytic growth of E. amylovora and subsequent disease. In several regions of the country, however, E. amylovora has become resistant to this antibiotic (7), and alternative chemicals provide only partial control (24).

In addition to chemical methods, biological suppression of blossom infection

Corresponding author: K. B. Johnson

E-mail: johnsonk@bcc.orst.edu

Support was provided by the Winter Pear Control Committee, Milwaukie, OR and the USDA NRICGP.

Accepted for publication 22 August 2003.

Publication no. D-2003-1106-01R

(C) 2004 The American Phytopathological Society can be achieved by inoculating floral surfaces with strains of bacteria antagonistic to E. amylovora $(4,5,8,9,30)$. For example, the bacterium Pseudomonas fluorescens strain A506 is registered as a microbial pesticide (BlightBan A506; NuFarm Americas Inc., Houston, TX) for fire blight suppression, and other bacteria (notably strains of Pantoea agglomerans) are being developed for the same purpose (4). Adoption of biological control of fire blight by orchardists has been moderately successful. Extensive adoption, however, has been hindered by variation in efficacy and by a lack of knowledge as to how to optimally utilize biocontrol technologies within conventional management systems (4). For numerous foliar diseases suppressed by chemicals, environmentally based warning systems have been developed and adopted to time of the use of chemical agents (31). Potentially, development of similar systems for microbial agents could improve the effectiveness of biocontrol strategies (19).

Temperature regulates epiphytic growth and blossom-to-blossom spread of E. amylovora and, thus, is an important predictor of fire blight risk $(2,13,18,20,22,28)$. Several temperature-based predictive models have been developed to assess the risk of a blossom infection and, therefore, aid decisions on the need for chemical control. For example, the COUGARBLIGHT model (20) uses a 4-day moving total of degree hours above $15.5^{\circ} \mathrm{C}$ to assess infection risk. Similarly, the MARYBLYT model (22) assesses infection risk by summing degree hours above $18^{\circ} \mathrm{C}$, starting at the bloom stage of "full pink". These models, however, are not as useful for timing applications of biological agents because the bacterial antagonists must be introduced to the target sites with sufficient lead time to allow for growth of the microbes to an effective population size (4). Consequently, any model developed to optimize biological control of fire blight must utilize environmental information in such a way as to maximize the potential for the introduced agent to interact effectively with the pathogen.

Little research has been done to address the question of how to optimize the use of forecasting models when restricted by agents that require time after application to achieve optimal effectiveness. For biological control of fire blight, specifically, knowledge of temperature relationships among bacterial biocontrol agents and the pathogen could provide two benefits leading to improved use of this technology: (i) the ability to identify conditions favorable for establishment and growth of bacterial antagonists in pear and apple blossoms, and (ii) the ability to introduce antagonists into orchards with the lead time required for these bacteria to preemptively colonize floral surfaces prior to a period of high fire blight risk. Therefore, the first objective of this study was to conduct a comparative analysis of the effects of temperature on growth of two species of antagonistic bacteria on apple and pear blossoms relative to growth of E. amylovora. This knowledge then was combined with an analysis of the accuracy of extended temperature forecasts, with the goal of developing rules to guide timings of antagonist treatments in orchard environments.

\section{MATERIALS AND METHODS}

Bacterial strains. Pseudomonas fluorescens strain A506 (A506), Pantoea agglomerans strain C9-1S (C9-1S, synonym E. herbicola $\mathrm{C} 9-1 \mathrm{~S})$, and E. amylovora strain $153 \mathrm{~N}$ (Ea153N) were used in all experiments described below. A506, isolated by $\mathrm{S}$. Lindow $(8,9)$, is used commercially for fire blight suppression (BlightBan A506; NuFarm Americas Inc.). C9-1S is derivative of strain C9-1, which was isolated by C. Ishimaru (3). Both A506 and C9-1S are resistant to streptomycin and rifampicin. Ea153N is a spontaneous, nalidixic, acid-resistant derivative of a strain obtained from an Oregon apple orchard (5). Freeze-dried preparations of all three strains were prepared using methods 
described previously (23) and stored at $-50^{\circ} \mathrm{C}$; titers of these preparations ranged from $1 \times 10^{10}$ to $1 \times 10^{11} \mathrm{CFU} \mathrm{g}^{-1}$ and were reevaluated periodically by dilution plating.

Growth chamber experiment. Experiments to measure the effect of constant temperatures on growth rates of bacterial strains on stigmatic surfaces of pear and apple blossoms were conducted during spring 2000 and 2001 in four or five nonlighted growth chambers (VWR Scientific Model 2105; Sheldon Mfg., Inc., Cornelius, OR). At the start of an experimental replication, temperature treatments of 6,9 , 12,15 , and $18^{\circ} \mathrm{C}$ were assigned randomly to each of the growth chambers $\left(18^{\circ} \mathrm{C}\right.$ was a treatment in 2001 only). The temperature in each chamber was monitored with a mercury thermometer as well as a recording, electronic temperature sensor (Hobo Temp; Onset Computer Corp., Pocasset, MA). The experiment was arranged as a randomized complete block design with four (2000) or five (2001) temperature treatments, three bacterial strain treatments, and six (2000) or eight (2001) replications blocked over time. Individual replications were inoculated between 23 March and 23 April 2000, and between 3 April and 1 May 2001. Pear blossoms (cv. Bartlett) were used for the first two replications in the 2000 experiment and for the first four replications in 2001. Apple blossoms (cv. Red Delicious) were used for the final four replications in both years.

Blossoms for the experiments were obtained from field-grown trees located at the Oregon State University Department of Botany and Plant Pathology Field Laboratory near Corvallis, OR. Blossom-bearing branches were pruned from trees 4 to 5 days before first bloom and stored at $5^{\circ} \mathrm{C}$ with the basal ends submerged in water. At the start of an experimental replication, branches were removed from the cold room and incubated in the laboratory (20 to $23^{\circ} \mathrm{C}$ ), where blossoms opened within 1 to 2 days. Following protocols of Pusey (16), new blossoms (cupped petals and red anthers) were harvested with peduncle intact (1.5 cm in length) and placed onto 80-well, polypropylene microcentrifuge tube racks (Fisher Scientific, Pittsburgh, PA) with the basal ends of the peduncles submerged in sterile 10\% sucrose. Suspensions of A506, C9-1S, and Ea153N were prepared by resuspending freeze-dried preparations in sterile distilled water to achieve a concentration of $1 \times 10^{7} \mathrm{CFU} / \mathrm{ml}$. These suspensions were misted onto blossoms to near runoff using a reagent atomizer (Kontes Glass Co., Vineland, NJ). Racks holding inoculated blossoms were transferred to 10-liter plastic, lidded boxes (Rubbermaid, Wooster, $\mathrm{OH}$ ), the floors of which were flooded with 1 liter of a $40 \%$ glycerol solution (vol/vol) to maintain a relative humidly of 93 to $94 \%$ (17). Boxes containing the racks of blossoms then were placed into growth chambers. For each replication, 15 blossoms were inoculated within each strain-temperature combination.

Population sizes of the bacterial strains on individual blossoms were determined by dilution plating. Sampling times were 0 , 24, 48, 96, and $144 \mathrm{~h}$ (i.e., 0, 1, 2, 4, and 6 days) after inoculation; three blossoms were sampled at each sampling time. For each blossom, the pistils, including the stigmas (24), were removed and placed into $1 \mathrm{ml}$ of sterile $10 \mathrm{mM}$ potassium phosphate buffer, pH 7.0. Racks of test tubes holding the pistils in buffer were sonicated and vortexed (5) to dislodge the bacteria from the plant surfaces. Subsequently, the blossom wash and two serial 100-fold dilutions were spread onto selective culture media as described previously $(5,23)$.

Screenhouse experiment. Growth rates of the selected bacterial strains also were examined under fluctuating temperature conditions on pear and apple trees growing in an unheated, 15.5-by-60-m screenhouse located at the Oregon State University Department of Botany and Plant Pathology Field Laboratory near Corvallis, OR during spring 2001 and 2002. Trees in the screenhouse ranged from 3 to 7 years old and were protected from rain and ultraviolet radiation by a translucent, fiberglass roof, and from insect visitations by a 2-by-2-mm steel screen walls. As in the growth chamber experiments, blossoms of pear (Pyrus calleryana cv. Aristocrat or $P$. communis cv. Bartlett) or apple (Malus $\times$ domestica cvs. Snowdrift or Golden Delicious) were spray inoculated with suspensions of A506, C9-1S, or Ea153N. Cultivars in the screenhouse were chosen to create a nearly continuous, 5- to 6-week period of bloom, which allowed an inoculation/96-h incubation protocol to be repeated nine times each year (two or three sequential inoculations per cultivar). An additional temperature treatment was created by enclosing some replicates of individual trees in clear, polyethylene sheeting $(0.15-\mathrm{mm}$ thickness), and warming them continuously with a 100-W light bulb. The enclosures had dimensions of 1.7 by 1.7 by $2.0 \mathrm{~m}$ (height) with frames constructed of 2.5cm-diameter polyvinyl chloride pipe; the sheeting was secured to the frames with spring-loaded clamps immediately after the inoculation. All replications of the inoculation/incubation protocol were initiated in the morning between 8:00 and 10:00 A.M.

To initiate an experimental replication, individual branches on each of six trees (three enclosed and three nonenclosed) randomly were assigned a bacterial strain treatment. On each branch, eight new blossoms (red anthers) were marked by securing color-coded tape around the peduncle. Suspensions of bacterial strains $\left(1 \times 10^{7}\right.$ $\mathrm{CFU} / \mathrm{ml}$ ) were prepared as described above and misted onto blossoms to near runoff with hand-held, adjustable trigger sprayers (0.2-liter capacity). For each strain, 24 marked blossoms (4 from each of the enclosed trees and 4 from each of the nonenclosed trees) were sampled $30 \mathrm{~min}$ after inoculation; the other 24 blossoms were sampled after $96 \mathrm{~h}$ of incubation. Samples were transported to the laboratory; the population sizes of inoculated strains on individual blossoms were estimated as described above $(5,23)$.

Ambient screenhouse and enclosure temperatures were monitored and recorded with electronic temperature sensors (Hobo Temp) set to hourly sampling intervals. Two to four sensors that measured ambient temperatures in the vicinity of treated trees were suspended from the roof at a height of $1.5 \mathrm{~m}$. Similarly, two sensors were hung on tree branches in each of the enclosures. A subset of these sensors also recorded relative humidity inside and outside of the chambers.

Bacterial growth rate analysis. Data from the growth chamber experiments were subjected to two analyses to examine effect of temperature on growth of the bacterial strains on stigmas of pear and apple. In the first analysis, estimates of bacterial population size (i.e., CFU) on individual blossoms were transformed $\log _{10}(y)$ (11) and mean population size for each combination of strain and temperature treatment was plotted in temporal arrays as a function of hours after inoculation. Relative area under curve for mean population size $\left(A_{\text {pop }}\right)$ was computed from the logtransformed data:

$$
A_{\mathrm{pop}}=\sum_{i=2}^{n}\left[\left(y_{i}+y_{i-1}\right) / 2 \cdot\left(t_{i}-t_{i-1}\right)\right] /\left(t_{n}-t_{1}\right)
$$

where $y$ and $t$ are the values of mean population size (log-transformed) and hours after inoculation, respectively, for the $i$ th sample date, and $n$ is the total number of sample dates during the experiment. Values of $A_{\text {pop }}$ were subjected to analysis of variance (ANOVA) (Proc GLM ver. 7.0; SAS Institute, Inc., Cary, NC) to determine the effects of strain and temperature.

For the second analysis, natural $\log$ and $\operatorname{logit}(\ln [y /(K-y)])$ transformations were applied to the population size data. An intrinsic growth rate (proportional increase of bacterial population per hour; $\mathrm{h}^{-1}$ ) was computed for each strain at each temperature by regressing (Proc REG; SAS Institute) the overall means of transformed data on hours after inoculation. Because of difficulty in choosing or estimating a common value of $K$ (i.e., the upper, asymptotic limit to population size) among strains, temperatures, and experiments, we based further analyses on growth rates computed from natural log-transformed data sampled during the first $96 \mathrm{~h}$ of the experiment. Estimates of growth rates derived from natural log transformations were regressed on incubation temperature and examined for linearity and for temperatures below which little growth was 
observed (i.e., lower or base temperature limits). Indicator variable regression (14) was used to evaluate if the observed growth rate responses to temperature differed among the bacterial strains.

For the screenhouse experiment, estimates of bacterial population size on individual blossoms (CFU/blossom) were transformed $\log _{10}(y)$. Mean population sizes for each combination of strain and temperature treatment were plotted against total degree hours accumulated during each 96-h incubation period. Total degree hours were obtained by averaging measurements obtained for each hour across all sensors from the same environment (i.e., ambient or enclosed), and then summing over the 96-h period the positive differences obtained after subtraction of a chosen base temperature (e.g., $10^{\circ} \mathrm{C}$ ) from each hourly mean. Again, estimates of intrinsic growth rate $\left(\mathrm{h}^{-1}\right)$ for a bacterial strain during an incubation period were computed from the exponential function as

$$
r=1 / 96 \cdot\left[\ln \left(y_{96}\right)-\ln \left(y_{\text {zero }}\right)\right]
$$

where $y_{\text {zero }}$ and $y_{96}$ are the mean bacterial population sizes near the time of inoculation and after $96 \mathrm{~h}$, respectively. Growth rate estimates were related to total degree hours experienced during each 96-h incubation period with second-order polynomial regression models. Because of the difficulty of comparing polynomial models statistically, differences in growth rate estimates among bacterial strains were compared visually and with a paired $t$ test procedure (21).

Bacterial growth index. The analysis of bacterial growth rates indicated that a degree hour model with a base temperature lower than that used commonly for prediction of fire bight risk could be potentially valuable for predicting conditions favorable for introduction of bacterial antagonists into orchard environments. To examine the utility of such a model, we compared 4-day moving totals of degree hours base $10^{\circ} \mathrm{C}$, termed the "bacterial growth index", to similar degree hour totals at base $15.5^{\circ} \mathrm{C}$, which we termed the "disease risk index" (note: this is the same concept and base temperature used to assess disease risk in the COUGARBLIGHT model [20], but we employed a different method of degree hour estimation that results in slightly different values). Temperature data were from six apple- or pearproduction areas in the Pacific Northwest: Rogue Valley near Jacksonville in southwestern Oregon, Hood River Valley near Pine Grove in north-central Oregon, Walla Walla Valley near Milton-Freewater in northeastern Oregon, Yakima Valley near Yakima in south-central Washington, Columbia Valley near Wenatchee in central Washington, and the Okanogan Valley near Okanogan in north-central Washington. Records of daily maximum and minimum temperature measured at a field station in each production area were obtained for periods of pear and apple bloom (lateMarch to mid-May) during 1999, 2000, and 2001 (these data are available online from the Pacific Northwest Cooperative Agricultural Weather Network, United States Bureau of Land Reclamation, Boise, ID). Daily maximum and minimum temperatures were converted to degree hour estimates with the following algorithm:

$$
\begin{gathered}
D H_{\text {base }}=1 / 2 * \operatorname{MAX}\left(T_{\max }-T_{\text {base }}, 0.0\right) * \\
\left(\left\{\left(T_{\max }-T_{\text {base }}\right) /\left[\left(T_{\max }-\text { today's } T_{\min }\right) / 10\right]\right\}+\right. \\
\left.\left\{\left(T_{\max }-T_{\text {base }}\right) /\left[\left(T_{\max }-\text { tomorrow's } T_{\min }\right) / 14\right]\right\}\right)
\end{gathered}
$$

where $T_{\max }$ and $T_{\min }$ are daily minimum and maximum temperatures, $T_{\text {base }}$ is the selected base temperature, and $D H_{\text {base }}$ is the estimated degree hours at the selected base temperature. Prior to application to the 1999 and 2000 data, the algorithm was evaluated with daily and hourly temperature records for Medford and Corvallis, OR over the period from mid-March to early May 1998. After this evaluation, estimated values of the bacterial growth index were regressed on the estimated disease risk index values. In addition, predicted values of the bacterial growth index at key values of the disease risk index were noted; these values approximated transitions in the COUGARBLIGHT model (20) from low to moderate and moderate to high disease risk.

Accuracy of indices estimated from extended temperature forecasts. Accu-
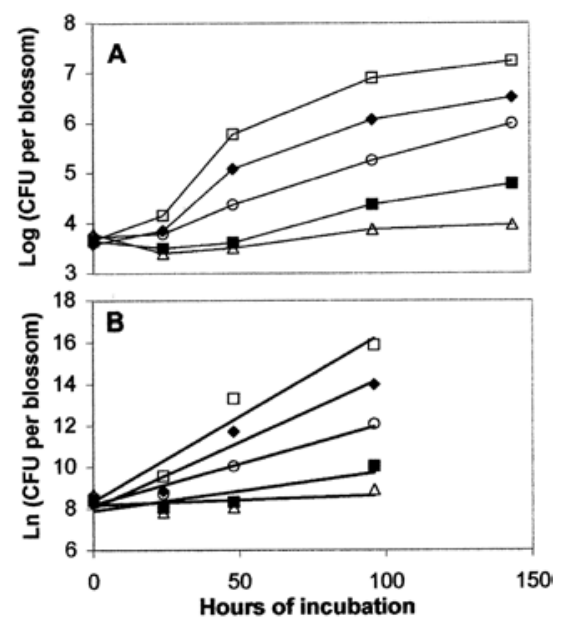

Fig. 1. A, Logarithm (base 10) of the population size (CFU/blossom) of Erwinia amylovora strain $153 \mathrm{~N}$ on detached blossoms of pear or apple after $0,24,48,96$, and $144 \mathrm{~h}$ of incubation at constant temperatures of $6(\triangle), 9(\boldsymbol{\square})$, $12(\mathrm{O}), 15.5(\diamond)$, or $18^{\circ} \mathrm{C}(\square)$. Blossoms were forced from field-grown branches, and maintained detached with peduncle in $10 \%$ sucrose. The inoculum suspension $\left(1 \times 10^{7} \mathrm{CFU} / \mathrm{ml}\right)$ was misted onto blossoms to near runoff. B, Natural $\log$ of the population size of E. amylovora strain $153 \mathrm{~N}$ regressed on hours of incubation. Regressions equations are: $6^{\circ} \mathrm{C}, y=8.12+$ $0.005 x\left(r^{2}=0.14\right) ; 9^{\circ} \mathrm{C}, y=7.90+0.019 x\left(r^{2}=\right.$ $0.72) ; 12^{\circ} \mathrm{C}, y=8.21+0.039 x\left(r^{2}=0.96\right)$; $15.5^{\circ} \mathrm{C}, y=8.03+0.063 x\left(r^{2}=0.96\right)$; and $18^{\circ} \mathrm{C}, y=8.37+0.082 x\left(r^{2}=0.95\right)$. racy of 3- and 4-day forecasts of degreehour totals were evaluated for the same six Oregon and Washington pome fruitproduction areas listed above. Forecasts of daily maximum and minimum temperatures for each production area were obtained from a commercial forecasting service (P. Volker, Extended Range Forecasting, Portland, OR). To fill in for occasional missing values, backup sets of forecasts for each production area were obtained by archiving data published daily on a weather information website (The Weather Channel Enterprises, Inc., Atlanta, GA). As with the actual temperature data, daily degree hour forecasts (base 10 and $15.5^{\circ} \mathrm{C}$ ) were estimated with the algorithm described above. Index values derived from actual and forecasted temperatures in each production area were plotted in graphical arrays. For each spring season, actual daily index values were regressed on the corresponding 3- and 4-day forecasts of each index.

\section{RESULTS}

Growth chamber experiment. Each inoculated bacterial strain was established on blossom surfaces and recovered in blossom washes over the time course of the experiment. In general, measured population sizes of the strains increased with hours of incubation for all temperature treatments, except for E. amylovora at $6^{\circ} \mathrm{C}$. All strains showed a similar pattern of growth over time: initial population sizes of $1 \times 10^{3}$ to $1 \times 10^{4} \mathrm{CFU} / \mathrm{blossom}$, a rapid increase in population size between 24 and $96 \mathrm{~h}$ after inoculation, and, at higher temperatures $\left(15\right.$ and $\left.18^{\circ} \mathrm{C}\right)$, a dampening of the growth rate between 96 and $144 \mathrm{~h}$ of

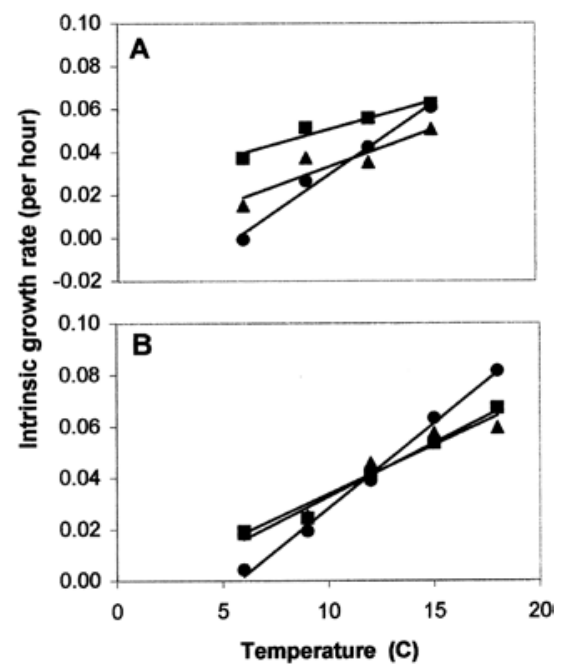

Fig. 2. Estimates of intrinsic growth rates $\left(\mathrm{h}^{-1}\right)$ of Erwinia amylovora strain $153 \mathrm{~N}(\bullet)$, Pantoea agglomerans strain C9-1S (ム), and Pseudomonas fluorescens strain A506 (ם) on detached pear or apple blossoms regressed on incubation temperature in growth chambers held at constant temperatures of $6,9,12,15.5$, or $18^{\circ} \mathrm{C}$ for experiments conducted in $\mathbf{A}, 2000$ and $\mathbf{B}, 2001$. 
incubation (data for E. amylovora is shown as an example; Fig. 1A). At the higher temperature treatments, E. amylovora attained population sizes in the range of $1 \times$

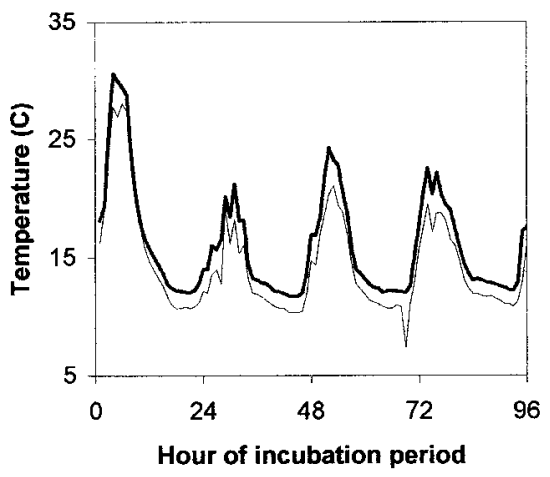

Fig. 3. Example of the diurnal pattern of temperatures measured in a screenhouse containing pear and apple trees during one $96-\mathrm{h}$ incubation period in spring 2002. Lower curve is the ambient temperature as recorded by sensors suspended from the screenhouse roof at a height of $1.5 \mathrm{~m}$. Upper (boldface) curve is the temperature measured inside of $1.7 \times 1.7 \times 2$ m polyethylene film chambers within which some of the trees inoculated with bacterial strains had been enclosed. These chambers were heated constantly with a 100-W light bulb. Each incubation period was initiated at approximately 9:00 A.M.
$10^{6}$ to $1 \times 10^{7} \mathrm{CFU} / \mathrm{blossom}$; maximum population sizes of A506 and C9-1S did not exceed $1 \times 10^{6} \mathrm{CFU} / \mathrm{blossom}$. Analysis of variance of relative area under the population size curve resulted in a highly significant $(P<0.0001)$ effect of temperature and of strain, but a nonsignificant $(P>$ $0.05)$ interaction term.

With two exceptions, regression of the natural $\log$ of population size measured over the first $96 \mathrm{~h}$ of incubation resulted in linear models with significant $(P \leq 0.05)$ coefficients of determination (average $r^{2}=$ 0.92 ; data for E. amylovora is shown as an example; Fig. 1B); the two exceptions were the 2000 and 2001 models derived for E. amylovora at $6^{\circ} \mathrm{C}$, where little increase in population size was observed. Intrinsic growth rates ranged from near $0.0 \%$ per hour (E. amylovora at $6^{\circ} \mathrm{C}$ ) to $8.2 \%$ per hour (E. amylovora at $18^{\circ} \mathrm{C}$ ). For all strains, estimated intrinsic growth rates could be described as a linear function of incubation temperature (Fig. 2). Notably, in both years, the regression of intrinsic growth rate on temperature resulted in similar slope parameters for strains A506 and $\mathrm{C} 9-1$, but a significantly $(P=0.009$ and 0.002 for experiments conducted in 2000 and 2001, respectively) steeper growth rate response for $E$. amylovora. Compared with the pathogen, the antago- nist strains had higher growth rates at 6 and $9^{\circ} \mathrm{C}$, but, because of the steeper slope, the growth rate of E. amylovora was similar to or surpassed the other strains at the higher temperature treatments.

Screenhouse experiment. As expected, temperatures in the screenhouse fluctuated diurnally (one of the 96-h incubation periods is shown as an example; Fig. 3). Temporal sequencing of experimental replications on different pear and apple cultivars and enclosing some trees in heated plastic chambers both were effective in increasing the range of temperature variation observed across the replicates. For example, for trees growing under ambient conditions, degree hours base $10^{\circ} \mathrm{C}\left(\mathrm{DH}_{10}\right)$ per 96-h incubation period ranged from 99 to 487 for Aristocrat pear, 175 to 424 for Bartlett pear, 85 to 331 for Snowdrift apple, and 239 to 716 for Golden Delicious apple. Hourly temperatures measured in the heated chambers were an average of $2.0^{\circ} \mathrm{C}$ greater than temperatures measured under ambient conditions, which augmented $\mathrm{DH}_{10}$ for enclosed trees an average of 130 degree hour units per 96-h incubation period.

For all bacterial strains, final mean population size $\left(\log _{10}\right.$-transformed $\mathrm{CFU} /$ blossom) ranged from 2.4 to 7.8 , and was highly correlated to the number of degree
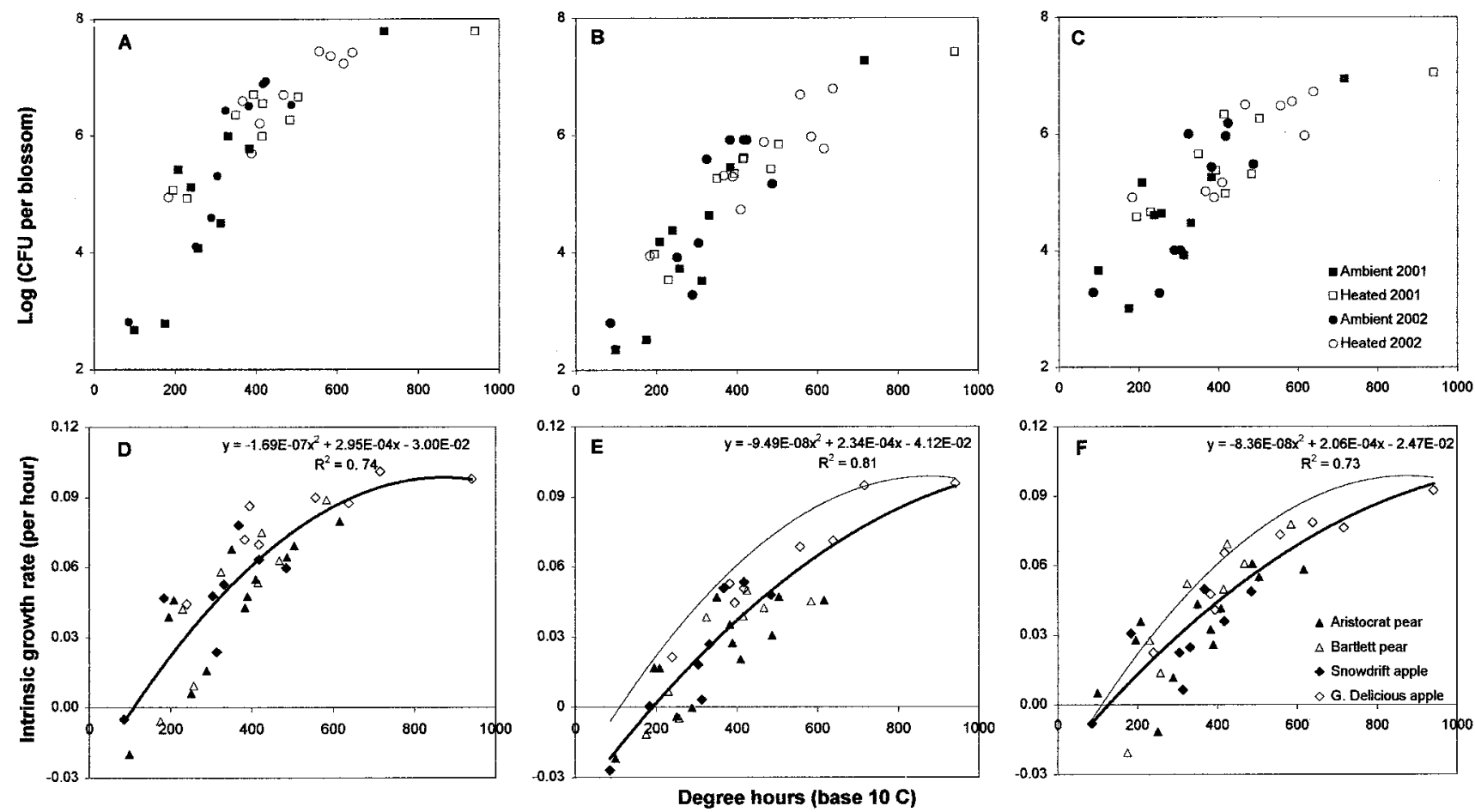

Fig. 4. Upper panels: population size ( $\log _{10}[\mathrm{CFU}$ per blossom]) of A, Erwinia amylovora strain 153N, B, Pantoea agglomerans strain C9-1S, and C, Pseudomonas fluorescens strain A506 on blossoms of screenhouse-grown pear or apple trees at $96 \mathrm{~h}$ after inoculation for experiments conducted in 2001 and 2002. Bacterial suspensions $\left(1 \times 10^{7} \mathrm{CFU} / \mathrm{ml}\right)$ were misted onto to blossoms to near runoff. Variation in degree hour totals was obtained by repeating the 96-h inoculation and incubation protocol nine times on four different pear and apple cultivars over a 5- to 6-week period. Enclosing some replicates of trees in polyethylene film chambers and heating the chambers with a 100-W light bulb created an additional treatment. Lower panels: estimated intrinsic growth rates $\left(\mathrm{h}^{-1}\right)$ of $\mathbf{D}$, E. amylovora strain 153N, E, Pantoea agglomerans strain C9-1S, and F, Pseudomonas fluorescens strain A506 on blossoms of screenhouse-grown pear or apple trees blossom regressed on total degree hours (base $10^{\circ} \mathrm{C}$ ) over a 96 -h incubation period. Markers indicate the pear or apple cultivar on which the bacterial growth rates were measured. Second-order polynomial regression functions (boldface lines) are shown in each panel; for comparison, the regression function obtained for E. amylovora also is shown as a thin line in panels E and F containing data for Pantoea agglomerans and Pseudomonas fluorescens. 
hours experienced during an incubation period (strain-specific correlation coefficients ranged from $r=0.82$ to $0.90, n=36$; Fig. 4). Based on a paired $t$ test, blossoms sampled from trees in enclosures supported significantly $(P<0.001)$ higher final bacterial population sizes than those sampled from nonenclosed trees.

Estimates of intrinsic growth rate regressed on total degree hours during a 96-h incubation period resulted in significant $(P$ $<0.0001)$ models for each of the strains. Intrinsic growth rates for E. amylovora were best described by a second-order polynomial function; significance of the second-order term was $P=0.004$ (Fig. 4D). For comparative purposes, secondorder polynomial functions also were fit to growth rate data for A506 and C9-1S (Fig. $4 \mathrm{E}$ and $\mathrm{F}$ ) although, in this case, the second-order coefficients were marginally significant $(P=0.10$ and 0.04 , respectively). Compared with the regression function that described the E. amylovora growth rate response, the functions derived for strains A506 and C9-1S were shifted to the right (Fig. 4E and F), indicating that, over the range of 200 to 900 cumulative $\mathrm{DH}_{10}$, the growth rates of the antagonists were consistently smaller than those observed for the pathogen. Paired $t$ test analyses confirmed this observation, with the differences in measured intrinsic growth rates of the antagonist strains subtracted from those obtained for Ea153N averaging $0.014 \mathrm{~h}^{-1}$ (standard error \pm $0.002, P \leq 0.001, n=36$ ) for A506 and $0.022 \mathrm{~h}^{-1}( \pm 0.002 ; P \leq 0.001)$ for $\mathrm{C} 9-1 \mathrm{~S}$.

Growth rate-degree hour relationships obtained in the screenhouse (where temperatures fluctuated diurnally) also were shifted to the right of relationships derived from the constant-temperature growth chambers. For example, in growth chambers, both A506 and C9-1S showed increases in population size and positive growth rates at the incubation temperature of $6^{\circ} \mathrm{C}$ (Fig. 2); however, in the screenhouse, these strains grew relatively poorly over the range of 0 to 200 cumulative $D H_{10}$ (Fig. 4D and E). Consequently, the most appropriate choice of temperature at which to base a degree hour model was dependent on the data source. For the modeling approach described below, we chose a base of $10^{\circ} \mathrm{C}$ because it represented a compromise between the results of the growth chamber and screenhouse studies, and because this temperature and its Fahrenheit equivalent $\left(50^{\circ} \mathrm{F}\right)$, both being multiples of ten, represent simple threshold values for implementation and discussion of this concept.

Relationship of bacterial growth index to fire blight risk index. For degree hours based either 10 or $15.5^{\circ} \mathrm{C}$, the regression of actual degree hours measured in Medford and Corvallis, OR in 1998 on those estimated from the algorithm using daily maximum and minimum temperatures resulted in models where the $\mathrm{y}$ inter- cept could be forced through zero with a slope coefficient near 1.0 (slope equaled 1.023 for $10^{\circ} \mathrm{C}\left[r^{2}=0.98\right]$ and 0.9994 for $\left.15.5^{\circ} \mathrm{C}\left[r^{2}=0.96\right] ; n=75\right)$.

Estimates of the bacterial growth index (4-day moving degree hour total, base $10^{\circ} \mathrm{C}$ ) during the bloom period in six pearand apple-production areas in 1999, 2000, and 2001 ranged from 62 to 1,138 , which was comparable to the range of $96-\mathrm{h}$ degree hour totals observed in the screenhouse experiment (85 to 941). The bacterial growth index regressed on the disease risk index resulted in a linear relationship with a y intercept of $240 \mathrm{DH}_{10}$ (Fig. 5). At the critical disease risk index values of 100 $D H_{15.5}$ (approximate shift from low to moderate infection risk in the COUGARBLIGHT model; 20) and $200 \mathrm{DH}_{15.5}$ (approximate shift from moderate to high infection risk in the COUGARBLIGHT model; 20), the regression model predicted corresponding bacterial growth index values of 444 and $647 \mathrm{DH}_{10}$, respectively.

Accuracy of indices estimated from extended temperature forecasts. Temporal arrays of forecasted and actual values of the bacterial growth and disease risk indices revealed a general correspondence of pattern (Fig. 6). Regression of actual values of the bacterial growth index and of the disease risk index on forecasted index values confirmed this correspondence, resulting in significant linear models $(P<$ 0.01 ) for both 3- and 4-day temperature forecasts in each of the observed seasons (Fig. 7). For the bacterial growth index, the actual values regressed on 4-day forecasts resulted in coefficients of determination that ranged from 0.59 (2000 season) to 0.81 (2001 season); coefficients of deter-

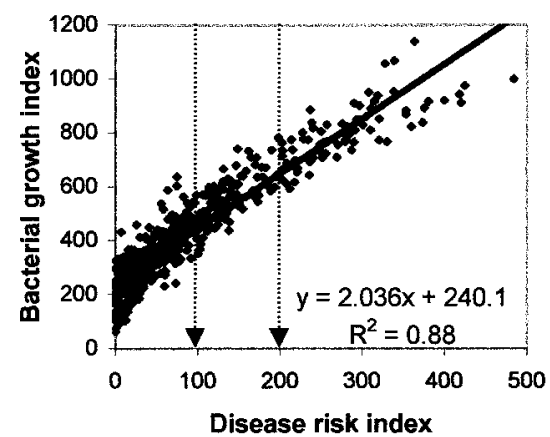

Fig. 5. Values of the bacterial growth index regressed on corresponding values of a disease risk index patterned after the COUGARBLIGHT model (20) as derived from daily maximum and minimum temperatures collected over 5- to 6-week periods of pear and apple bloom in six valleys within Oregon (Hood River, Rogue, and Walla Walla) and Washington (Okanogan, Wenatchee, and Yakima) during 1999, 2000, and 2001. The bacterial growth index represents a 4-day moving total of degree hours base $10^{\circ} \mathrm{C}$, whereas the disease risk index represents a 4-day moving total of degree hours base $15.5^{\circ} \mathrm{C}$. Arrows in the figure indicate where the disease risk index transitions from low to moderate (left arrow), and moderate to high (right arrow) infection risk (20). mination for the actual disease risk index regressed on the 4-day forecast ranged from 0.77 (2000 season) to 0.84 (2001 season). Similar results were obtained when actual index values were regressed on 3-day forecasts on index values, except that coefficients of determination were increased by approximately $10 \%$ compared with the 4-day forecast data.

\section{DISCUSSION}

Temperature can be an important factor regulating the growth of bacterial populations; knowledge of this fact has been employed in forecasting fire blight outbreaks for several decades $(2,13,18,20,22,28)$. Temperature also has been implicated as contributing to variability in biocontrol of this disease. For example, when daily temperatures averaged $6^{\circ} \mathrm{C}$, Nuclo et al. (15) observed poor establishment of A506 and C9-1S on pear blossoms. Similarly, Johnson et al. (6) observed that spread of C9-1S from colonized blossoms to previously unoccupied blossoms within the same tree or on neighboring trees was greatly re-
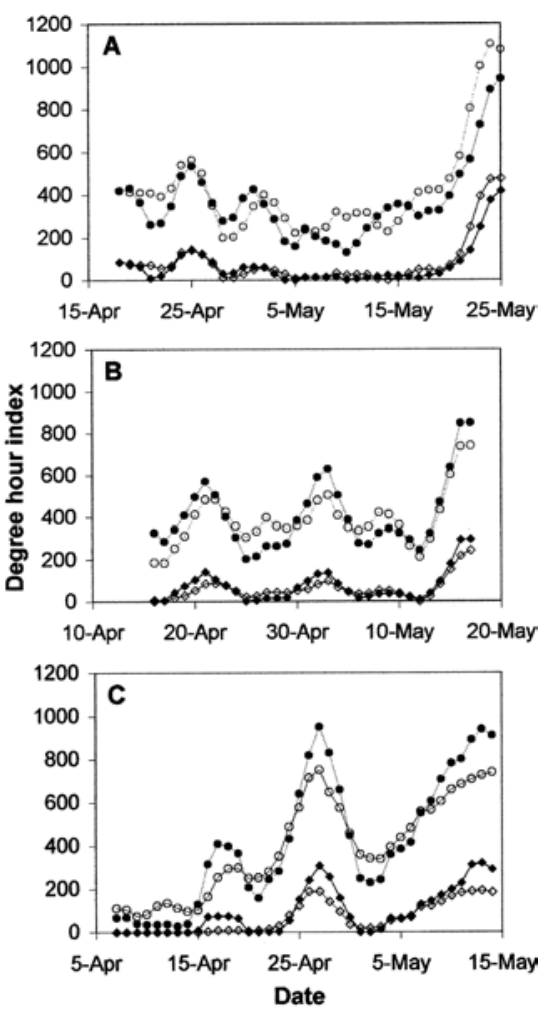

Fig. 6. Temporal arrays showing daily values of the actual bacterial growth index $(\bullet)$ and of the disease risk index patterned after the COUGARBLIGHT model (20) ( $\diamond$ ) compared with values of the same indices derived from 4day forecasts of daily maximum and minimum temperatures (open symbols). The bacterial growth index represents a 4-day moving total of degree hours base $10^{\circ} \mathrm{C}$, whereas the disease risk index represents a 4-day moving total of degree hours base $15.5^{\circ} \mathrm{C}$. Data were recorded at or forecasted for A, the Okanogan Valley, Washington in 1999, B, the Yakima Valley, Washington in 2000, and C, the Walla Walla Valley, Oregon in 2001. 

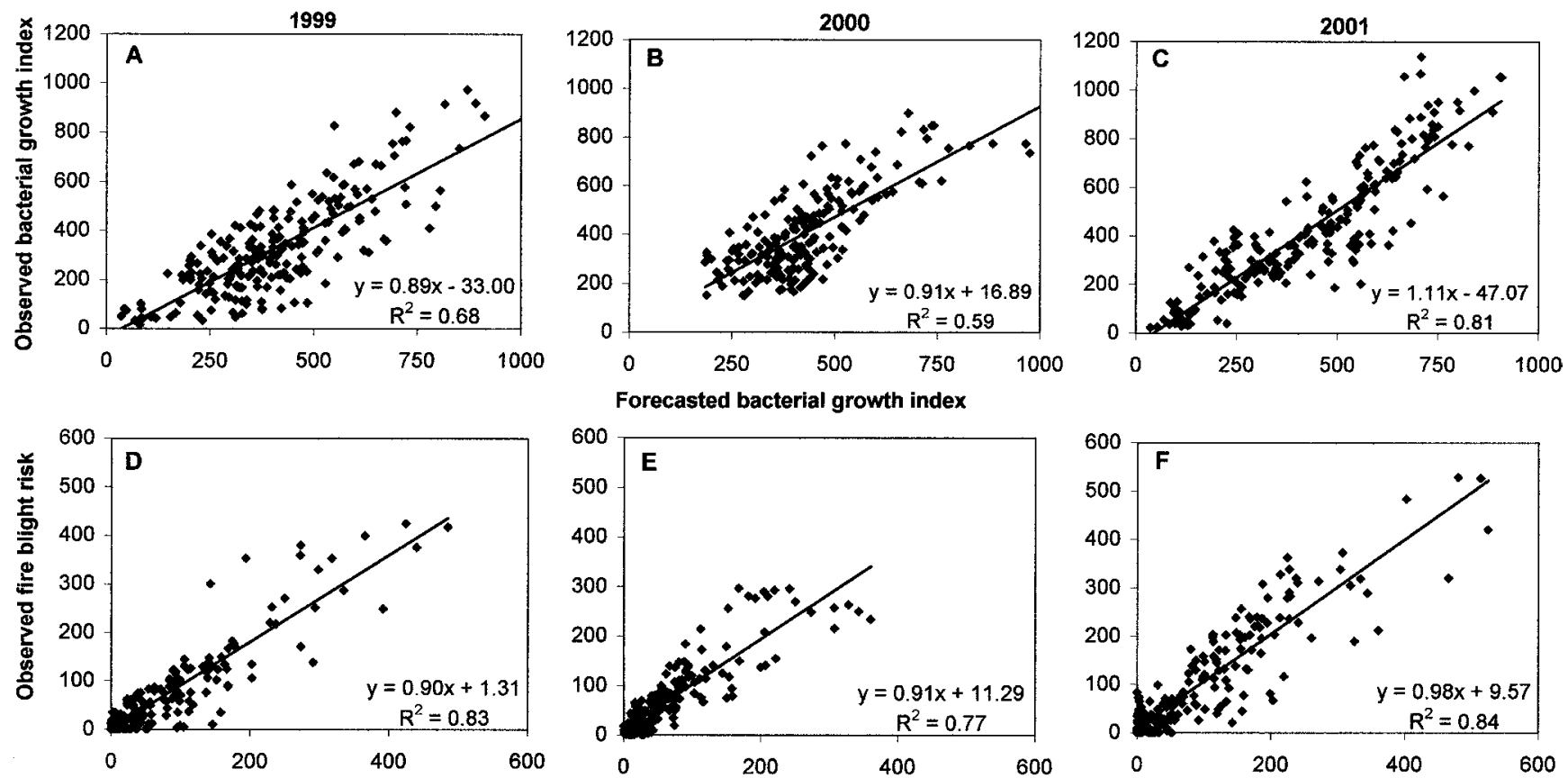

Forecasted bacterial growth index
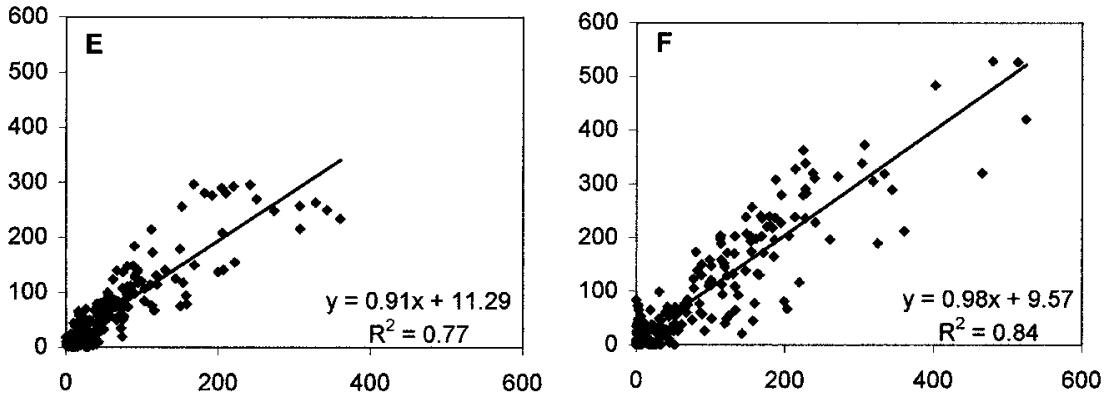

Forecasted fire blight risk (COUGARBLIGHT index)

Fig. 7. Regression of actual values of $\mathbf{A}, \mathbf{B}$, and $\mathbf{C}$, the bacterial growth index and $\mathbf{D}, \mathbf{E}$, and $\mathbf{F}$, the disease risk index pattered after the COUGARBLIGHT model (20) on values of the respective indices derived from 4-day forecasts of daily maximum and minimum temperature collected over 5- to 6-week periods of pear and apple bloom in six valleys within Oregon (Hood River, Rogue, and Walla Walla) and Washington (Okanogan, Wenatchee, and Yakima) during $\mathbf{A}$ and $\mathbf{D}, 1999, \mathbf{B}$ and $\mathbf{E}, 2000$, and $\mathbf{C}$ and $\mathbf{F}, 2001$. The bacterial growth index represents a 4-day moving total of degree hours base $10^{\circ} \mathrm{C}$, whereas the disease risk index represents a 4-day moving total of degree hours base $15.5^{\circ} \mathrm{C}$.

duced during periods of cold weather. In spite of these observations, quantification of the effect of temperature on growth rates of bacterial epiphytes on pear and apple blossoms has received little research effort. The results reported in this article represent a primary effort to measure and model growth rates of bacteria on floral surfaces, and to apply the results to the problem of optimizing the use of biological control for fire blight suppression.

The effect of temperature on growth rates of E. amylovora, Pseudomonas fluorescens, and Pantoea agglomerans were measured in two environments: constanttemperature growth chambers and an unheated screenhouse, where the temperatures fluctuated diurnally. The growth chamber experiment, performed with detached pear and apple blossoms, showed that intrinsic growth rates for the bacterial strains could be described as linear functions of incubation temperature, which is a general requirement for use the of degreehour concept to model biological processes (1). The growth chamber experiment also indicated that the two antagonists strains, A506 and C9-1S, had higher growth rates than the pathogen at the coldest temperatures evaluated $\left(6\right.$ and $\left.9^{\circ} \mathrm{C}\right)$, but that this advantage diminished at the hightemperature treatments $\left(15\right.$ and $\left.18^{\circ} \mathrm{C}\right)$. This result was not confirmed in the screenhouse experiment; however, in this environment, the data analyses indicated that $E$. amylovora had a higher growth rate than either of the two antagonist strains when exposed to the same heat unit accumulation
(Fig. 4E and F). The growth rate comparisons support the observations of Wilson and Lindow (30), who found that A506 suppressed epiphytic growth of E. amylovora when inoculated onto pear blossoms $24 \mathrm{~h}$ prior to the pathogen, but did not slow the growth rate of the pathogen when coinoculated onto floral surfaces.

The screenhouse experiment produced a broad and representative range of 96-h heat unit accumulations, and controlled for several factors that may have impacted the measured population sizes of bacteria in blossoms (e.g., rain [6], insects [4,5], and ultraviolet radiation [26]). The screenhouse did not, however, control for differences among the host cultivars in the suitability of the blossom surfaces for bacterial growth, or for variation in humidity among inoculation dates or among enclosed and nonenclosed trees. With regard to hosts, we concluded that the differences among the pear and apple cultivars as hosts for bacterial epiphytes were not a significant source of variation in this experiment (Fig. 4D$\mathrm{F})$; this is an observation we also have made previously (6). Humidity may be important (17), although we could not discern a consistent effect of this variable on measured bacterial growth rates. Measured relative humidity varied diurnally (typically from 40 to near 100\%) and among incubation periods owing to weather conditions outside the screenhouse. At times, the relative humidity measured for enclosed and nonenclosed trees varied by up to $10 \%$, with the ambient humidity measurements showing greater variability than those measured inside the plastic enclosures. Dew formation on blossoms was not observed during any of the 18 incubation periods.

Initially, the choice of the 96-h incubation period was dictated by the COUGARBLIGHT model (20), which is used widely for assessing fire blight risk in the Pacific Northwest. Over the course of the experiments, we concluded that the 96-h period was an excellent temporal unit for this system. This unit of time allowed the bacterial strains to colonize blossom surfaces under favorable temperature conditions, and avoided stagnation of growth rates, which occurred at high temperatures when incubation periods were extended to $144 \mathrm{~h}$. The 96-h incubation period allowed us to estimate bacterial growth rates that were comparable among strains and among experiments.

The bacterial growth index was patterned after the COUGARBLIGHT model and was developed to identify orchard conditions suitable for establishment and growth of bacterial biocontrol agents. Comparison of the bacterial growth index to the disease risk index provided insight as to how to optimize the timing of treatments of antagonists for fire blight suppression. For example, the approximate COUGARBLIGHT threshold that shifts disease risk from low to moderate $(100$ $\left.D H_{15.5}\right)$ translates to a bacterial growth index value of $444 \mathrm{DH}_{10}$ (Fig. 6). From the screenhouse data (Fig. 4B and C), 444 $\mathrm{DH}_{10}$ over a 96-h period allowed an inoculated antagonist to increase from near $10^{3}$ 
Table 1. Decision matrix designed to optimize the timing of introduction of bacterial antagonists into pear and apple orchards for the purpose of fire blight suppression

\begin{tabular}{|c|c|c|c|}
\hline \multirow[b]{2}{*}{ Assessed variable } & \multicolumn{3}{|c|}{ Timing of antagonist treatment relative to likelihood of effective disease suppression } \\
\hline & High likelihood & Intermediate & Low likelihood \\
\hline Host bloom stage & 25 to $90 \%$ & 5 to $20 \%$ or after $95 \%$ bloom & Prebloom or after petal fall \\
\hline Bacterial growth index ${ }^{a}$ & $>400$ degree-hours expected & 200 to 400 degree-hours expected & $<200$ degree-hours expected \\
\hline Disease risk index ${ }^{\mathrm{b}}$ & $<100$ degree-hours accumulated & 100 to 200 degree-hours accumulated & $>200$ degree-hours accumulated \\
\hline
\end{tabular}

a Forecasted 4-day total of degree-hours base $10^{\circ} \mathrm{C}$

b Actual degree hours base $15.5^{\circ} \mathrm{C}$. Patterned after the COUGARBLIGHT model (20) and corrected for when orchard comes into bloom.

CFU/blossom to a population size of $10^{5}$ to $10^{6} \mathrm{CFU} /$ blossom; populations of this size are in the range required to provide significant disease suppression $(4,5,9,16,24,30)$.

The second part of the optimization strategy was to evaluate 4-day temperature forecasts for their potential to provide an accurate prediction of the bacterial growth index and, consequently, the potential to increase the lead time required for preemptive establishment and growth of antagonist strains. Three seasons of spring temperature forecasts were obtained for six valleys in Oregon and Washington where pear and apple are grown. When data for these production areas were combined and regressed by season, significant models were developed relating actual values of the bacterial growth and disease risk indices to the forecasted values. The significance of these relationships led us to two common conclusions regarding the use of weather forecasts in disease management $(12,19)$. First, with $r^{2}$ values ranging from 0.59 to 0.84 over three seasons, we concluded that the 4-day forecast data contained useful, predictive information. Conversely, with 16 to $41 \%$ unexplained variation, temperature forecasts introduce an additional uncertainty to decision making, which must be weighed with other situational factors in an orchard management process (12).

Overall, the bacterial growth rate relationships, the development of a bacterial growth index patterned after the COUGARBLIGHT model, and the temperature forecast analysis indicate that a strategy can be developed to optimize the use of bacterial antagonists in fire blight management programs. This strategy is demonstrated in a decision matrix (Table 1) that promotes preemptive establishment of bacterial antagonists in blossoms in three ways: (i) treat the trees early in bloom, prior to significant colonization of blossoms by the pathogen or other indigenous bacterial epiphytes $(4,10,25)$; (ii) use 4-day forecasts of the bacterial growth index to identify when orchard conditions will be conducive to establishment and growth of bacterial antagonist populations; and (iii) use actual (and predicted) estimates of the disease risk index to time antagonist treatments early in the risk period. The decision matrix also indicates intermediate timings for treatment, recognizing that the high likelihood indicators for all three criteria may not occur in every situation. Although this decision matrix requires further validation, the rules within the matrix are based on years of observation $(4-6,10,15,23-25)$, experimentation (Fig. 4), and analysis (Figs. 5-7). For example, in a previous study (15), knowledge of the forecasted bacterial growth index would have allowed us to avoid poor conditions for antagonist establishment and growth. Thus, we expect that orchard managers who follow the matrix guidelines to deploy the recommended treatments of bacterial antagonists $(4,10)$ will achieve greater consistency in fire blight suppression.

\section{ACKNOWLEDGMENTS}

We thank L. Coop, Integrated Plant Protection Center, Oregon State University for assistance with retrieval and archiving of temperature forecast data.

\section{LITERATURE CITED}

1. Baskerville, G. L., and Emin, P. 1969. Rapid estimation of heat accumulation from maximum and minimum temperatures. Ecology 50:514-517.

2. Billing, E. 1976. Weather and fire blight in England. Ann. Appl. Biol. 82:259-266.

3. Ishimaru, C. A., Klos, E. J., and Brubaker, R. R. 1988. Multiple antibiotic production by Erwinia herbicola. Phytopathology 78:746750 .

4. Johnson, K. B., and Stockwell, V. O. 1998. Management of fire blight: A case study in microbial ecology. Annu. Rev. Phytopathol. 36:227-248.

5. Johnson, K. B., Stockwell, V. O., McLaughlin, M. J., Sugar, D., Loper, J. E., and Roberts, R. G. 1993. Effect of bacterial antagonists on establishment of honey bee-dispersed Erwinia amylovora in pear blossoms and on fire blight control. Phytopathology 83:995-1002.

6. Johnson, K. B., Stockwell, V. O., Sawyer, T. L., and Sugar, D. 2000. Assessment of environmental factors influencing growth and spread of Pantoea agglomerans on and among blossoms of pear and apple. Phytopathology 90:1285-1294.

7. Jones, A. L., and Schnabel, E. L. 2000. The development of streptomycin-resistant strains of Erwinia amylovora. Pages 235-252 in: Fire Blight: The Disease and Its Causative Agent, Erwinia amylovora. J. L. Vanneste, ed. CAB International, London.

8. Lindow, S. E. 1985. Integrated control and role of antibiosis in biological control of fire blight and frost injury. Pages 83-115 in: Biological Control on the Phylloplane. C. E. Windels and S. E. Lindow, eds. American Phytopathological Society, St. Paul, MN.

9. Lindow, S. E., McGourty, G., and Elkins, R. 1996. Interactions of antibiotics with Pseudomonas fluorescens A506 in the control of fire blight and frost injury of pear. Phytopathology 86:841-848.
10. Lindow, S. E., and Suslow, T. V. 2003. Temporal dynamics of the biocontrol agent Pseudomonas fluorescens strain A506 in flowers in inoculated pear trees. Phytopathology 93:727-737.

11. Loper, J. E., Suslow, T. V., and Schroth, M. N. 1984. Lognormal distribution of bacterial populations in the rhizosphere. Phytopathology 74:1454-1460.

12. Magarey, R. D., Seem, R. C., Russo, J. M. Zack, J. W., Waight, K. T., Travis, J. W., and Oudemans, P. V. 2001. Site-specific weather information without on-site sensors. Plant Dis. 85:1216-1226.

13. Mills, W. D. 1955. Fire blight development on apple in western New York. Plant Dis. Rep. 39:206-207.

14. Neter, J., and Wasserman, W. 1974. Applied Linear Statistical Models. R. D. Irwin, Inc. Homewood, IL.

15. Nuclo, R. L., Johnson, K. B., Stockwell V. O., and Sugar D. 1997. Secondary colonization of pear blossoms by two bacterial antagonists of the fire blight pathogen. Plant Dis. 82:661668.

16. Pusey, P. L. 1996. Crab apple blossoms as a model for research on biological control of fire blight. Phytopathology 87:1096-1102.

17. Pusey, P. L. 2000. The role of water in epiphytic colonization and infection of pomaceous flowers by Erwinia amylovora. Phytopathology 90:1352-1357.

18. Schroth, M. N., Thomson, S. V., Hildebrand, D. C., and Moller, W. J. 1974. Epidemiology and control of fire blight. Annu. Rev. Phytopathol. 12:389-412.

19. Shtienberg, D., and Elad, Y. 1997. Incorporation of weather forecasting in integrated, biological-chemical management of Botrytis cinerea. Phytopathology 87:332-340.

20. Smith, T. J. 1996. A risk assessment model for fire blight of apple and pear. Acta Hortic 411:97-104.

21. Steele, R. G. D., and Torrie, J. H. 1980. Principles and Procedures of Statistics, 2nd ed. McGraw-Hill, Inc., New York.

22. Steiner, P. W. 1990. Predicting apple blossom infections by Erwinia amylovora using the MARYBLYT model. Acta Hortic. 273:139148.

23. Stockwell, V. O., Johnson, K. B., and Loper, J. E. 1998. Establishment of two bacterial antagonists of Erwinia amylovora on pear and apple blossoms as influenced by inoculum preparation. Phytopathology 88:506513.

24. Stockwell, V. O., Johnson, K. B., Sugar, D., and Loper, J. E. 2002. Antibiosis contributes to biological control of fire blight by Pantoea agglomerans strain Eh 252 in the field. Phytopathology 92:1202-1209.

25. Stockwell, V. O., McLaughlin, R. J., Henkels, M. D., Loper, J. E., Sugar, D., and Roberts, R. G. 1999. Epiphytic colonization of pear stigmas and hypanthia by bacteria during primary bloom. Phytopathology 89:1162-1168.

26. Sundin, G. W., and Jacobs, J. L. 1999. Ultraviolet radiation (UVR) sensitivity analysis and UVR survival strategies of a bacterial 
community from the phyllosphere of fieldgrown peanut (Arachis hypogeae L.). Microb. Ecol. 38:27-38.

27. Thomson, S. V. 1986. The role of the stigma in fire blight infections. Phytopathology 76:476-482.

28. Thomson, S. V., Schroth, M. N., Moller, W. J., and Reil, W. O. 1982. A forecasting model for fire blight of pear. Plant Dis. 66:576-579.

29. Van der Zwet, T., and Beer, S. V. 1995. Fire blight-Its nature, prevention, and control: A practical guide to integrated disease management. U. S. Dep. Agric. Info. Bull. 631

30. Wilson, M., and Lindow, S. E. 1993. Interac- tions between the biological control agent Pseudomonas fluorescens strain A506 and Erwinia amylovora in pear blossoms. Phytopathology 83:117-123.

31. Zadoks, J. C. 1984. A quarter century of disease warning, 1958-1983. Plant Dis. 68:352-355. 